\title{
COMMENTARY
}

\section{Health care information: gold mine or mine field? \\ Collection, protection and utilization in Denmark's primary health care system}

\author{
JUSTIN C. MATUS ${ }^{1, *}$ \\ ${ }^{1}$ Wilkes University, USA
}

\begin{abstract}
The purpose of this article is to present an overview of the status of the Danish Health Care system's internal debate about the role of health care information. On the one hand, health information, when used appropriately can be a gold mine of information to help patients and in the development of policies and allocation of resources. On the other hand, concerns about patient privacy, unmasking of poor quality, monitoring, reduced autonomy and political agendas give rise to suspicion and fear, i.e., the mine field. An overview of the Danish health care system is presented with an emphasis on the perceived concerns and agendas of the various stakeholders. The perceived risks and benefits of collecting, protecting and utilizing health information is presented. The article concludes with a recommendation for greater cooperation among the various stakeholders.
\end{abstract}

JEL classification: I11, I18

Key words: health, information, patient, data, privacy, utilization

For many years Denmark has been held up as the model of an ideal healthcare system in terms of health information. In addition the features of universal coverage and a single payer model with good outcomes at a relatively efficient cost are among the key traits to which admirers point. However, as in many other prosperous and developed countries the advance and the expense of technology and higher expectations of patients have put pressure on all health care systems for more information and information technology, including Denmark’s. From 2007 to 2014, Denmark’s GDP spending on healthcare has steadily increased from $7.8 \%$ to more recently almost 8.9\% (Ministry of Health, 2017). These economic pressures are having several effects in Denmark including a hotly debated discussion about the collection, protection and utilization of health care information; and not simply patient information, but all aspects of health care information such as costs, productivity and outcomes, especially in the primary care arena. For example, should health information that has been collected to measure quality be subsequently used to determine budgets or measure physician productivity? The intent of this paper is to neither criticize nor compliment, but rather raise questions for the health care system itself to answer. In 2013 the Organization for Economic Cooperation and Development (OECD) wrote that,

* Correspondence to: Justin Matus, Wilkes University, 84 West South Street, Wilkes-Barre, PA 18766, USA. E-mail: justin.matus@wilkes.edu.

Published: Online June 2018. dx.doi.org/10.5617/njhe.5978 
“...Denmark has very good databases on quality of care but the goldmine is only partly exploited" (p19). The opposite side of the gold mine is a mine field of competing and conflicting stakeholders, each of whom has a legitimate argument for their priorities and concerns.

To better understand the present situation, a brief overview of the key stakeholders is appropriate (see figure 1). In 2007 Denmark undertook a major reform of its health care system, of which many details are very well explained by Christiansen (2012); Kristensen, T., Olsen, K. R., Kilsmark, J., Lauridsen, J. T. \& Pedersen, K. M (2012); Andersen, P. T. \& Jensen, J. (2010); and Vrangnaek (2016). The highlights of this reform, for the purpose of this paper, include the reorganization of three distinct levels with a variety of authorities and responsibilities. The first, and highest level is at the national level, the Ministry of Health. The Ministry is responsible for centralized financing and oversight of quality. The second highest authority are the five new Regions. The primary function of the Regions is to manage hospitals (both somatic and psychiatric) as well as health insurance (Andersen, P. T. \& Jensen, J., 2010). Regions are also expected to encourage their municipalities to engage in health prevention. The Regions are financed $80 \%$ from the state and the remaining $20 \%$ from the municipalities. Since the Regions lack any direct taxing authority many observers consider their policy influence policy to be somewhat muted. Finally at the front lines of medicine are the Municipalities. There were formerly 14 counties and 215 municipalities which were ultimately consolidated into the current 98. The Municipalities' primary responsibility is health promotion and the delivery of primary care in collaboration with General Practioners. The three layers are represented as a single stakeholder, i.e., the government. Obviously within these layers there is some competition and conflict of interest as well as synergies.

Figure 1: Health system stakeholders

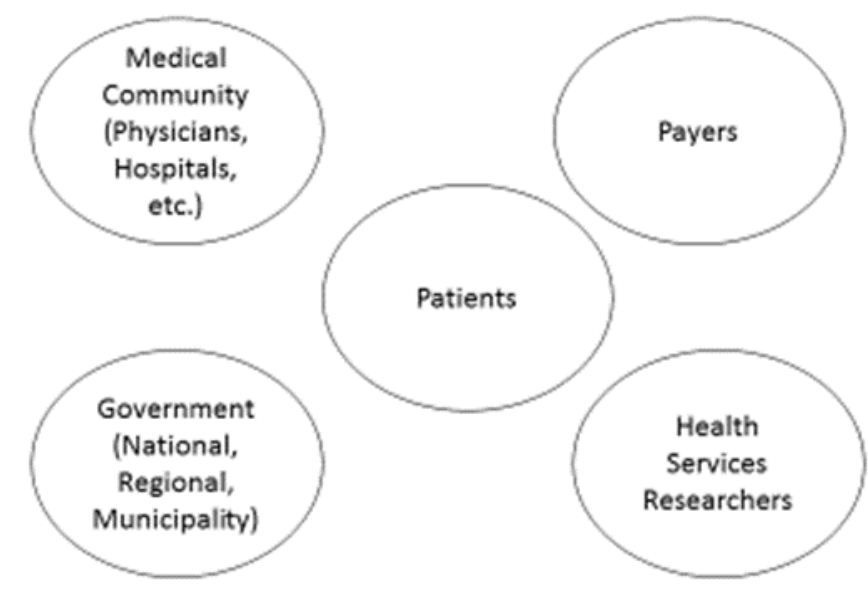

Figure 1

The second stakeholder group are the patients. Most would agree they are the most important group, yet most basic and least complex of all the stakeholders in terms of their needs. The third group of stakeholders is the medical community. Like the government stakeholders, there are fractions, such as general practioners, specialists, nurses, clinical 
support staff, hospitals and private hospitals. The fourth group is the payers. Payers include individuals, employers, insurance companies and taxpayers. These payers may make direct, indirect or combination of both types of payments. The fifth and final group of stakeholders is the health services research (HSR) community. The HSR community is both a consumer and producer of health information and are in many ways the most disadvantaged in terms of having any leverage or power to advance any agenda or priority.

In a perfect world, we would expect all the stakeholders to more or less work towards a common goal: the health of the patient and the community in a cost effective method whilst assuring high quality care. However, the reality is that health information has become a weapon or bargaining chip for any number of stakeholders to either attack or defend the position of one or more of the other parties, driven at least in part by the struggle to control information and control costs. Unfortunately, this focus on cost ignores equally important elements of health care policy, including choice and quality. As Figure 2 illustrates virtually any health care policy can be explained by this simple model. Regardless of how one thinks about how well or how poor a health care system is, you can simply apply the model and quickly realize that if you want more or less of something, all the other pieces are influenced. If patients want higher quality, then there will be either higher costs, less choice or some combination of all three. Quite simply, you cannot change one element of the model without changing the remaining elements.

\section{Figure 2: Health policy model}

Figure 2

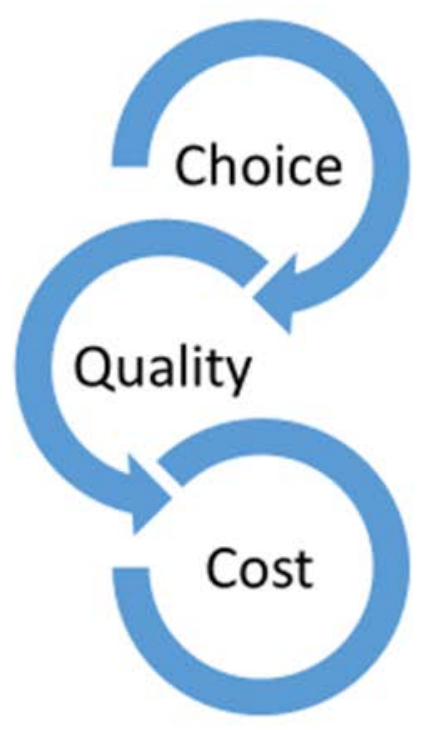

It is at this intersection of cost and quality that the debate has unfolded. Specifically there are three main issues regarding health information in Denmark: collection, protection and utilization. A brief discussion of each issue follows.

The first issue is the collection of health care information. From the moment a patient reaches out to her General Practioner or arrives at the emergency room, data is collected. However, there is not wide agreement over how much data should be collected, in what format, how often, how detailed and how accurate (Kierkegaard, 2013). The Danish 
National Patient Register (NPR) was first established in 1977. Since that time it has been used for a variety of research projects and policy decisions. However, the reliability and accuracy of the NPR has been called into question, due to changing definitions of codes. For example, "the variable patient type. Codes 0,1 , 2, and 3 have been used for this variable, but the meaning of the codes has changed over time. Code 2 was used for night patients up until 1987, thereafter it was used for outpatients”. (Lynge, E., Sandegaard, J. L., \& Rebolj, M., 2011, p. 32). It is not just the NPR that poses a problem. Researchers are often limited in their ability to make conclusive studies because of incomplete or biased data sets emanating from various clinics. In a recent study, (2014) Kristensen, T., Olsen, K. R., Schroll, H., Thomsen, J. L. \& Halling, A. utilized a data sample, which in their own words, "the sample of 59 sentinel GP clinics was not representative of Danish GP clinics. In 2010, only a limited number of GPs (3 - 4\%) coded sufficiently to qualify as sentinel GP clinics”. Anecdotal evidence via recent interviews with practicing GPs suggest that coding is much more improved, however there is some suggestion that this is also a generational phenomenon, with many GPs who are closer to retirement age have no interest in work which they see as having little value whereas the younger generation of GPs may be more inclined to code data.

The second issue is the protection of health care information, to include a patient's private information. Denmark has passed strict laws regarding the collection and dissemination of patient information. For example, recording a patient's height and weight in the medical record is private information and should be protected. On this matter, there is wide agreement. Within this electronic medical record, providers enter health information which, on the positive side, patients may easily access via the web site: Sundhed.DK. Using this same website, physicians may also look up information on a patient they are treating, to include prescriptions, for example. The benefits of this system to both patient and physician are obvious, at least in a very narrow and immediate sense. What is less clear is the best use of this individual data from a collective view or aggregate view or a long term view. Should this data be aggregated or trends analyzed? If so, by whom? This discussion however is not simply about patient information. There is information collected about physicians, the number of prescriptions they write, the number of patients they see, tests which are ordered and of course, the outcomes of patients associated with those treatments. Who should have access to these types of data? And again, for what purpose? Likewise there is information collected at the clinic level and hospital level and this information is also a gold mine of information, yet not necessarily well organized, standardized nor readily shared.

The third and final issue is the utilization of data. Perhaps most sensitive is the question of what do you do with the data once it has been collected? This is where the discussion really gets delicate because there are many concerns beyond privacy. For example, should one clinic or one physician be singled out in a public way for delivering substandard care? Are lay persons qualified to accurately interpret complex data? Should productivity and quality measures be used to determine budgets or compensation schemes? In the United States hospitals receive a score on each of 21 measures using a five star system (Agency for Healthcare Research and Quality, 2015). Would a Danish hospital want their hospital ranked as having 2.5 stars out of 5 ? Concerns about the accuracy of data remain at the forefront of many discussions, especially among those of whom are measured.

The future role of health care information may well be determined by the speed, breadth, and depth that Denmark embraces the concept of accreditation. The Danish Healthcare Quality Program has had a mandatory accreditation program for the secondary healthcare system since 2009. The value of accreditation of hospitals is manifest in many ways, including for example, shorter lengths of stay (Falstie-Jensen, A. M., Nørgaard, M., 
Hollnagel, E., Larsson, H., and Johnsen, S. P., 2015) and lower mortality (Falstie-Jensen, A. M., Larsson, H., Hollnagel, E., Nørgaard, M., Overgaard Svendsen, M. L., and Johnsen, S. P., 2015). A second significant step forward was began in 2014 when a mandatory process of accreditation for general practice was established. This accreditation program is managed by the Danish Institute for Quality and Accreditation in Healthcare (IKAS). During the next few years IKAS will be collecting data from GPs regarding their prescribing history for patients age 65 and higher using a base line and follow up methodology in order to evaluate patient outcome (Andersen, et al., 2017). While this is by no means a comprehensive evaluation, it is a very positive first step in connecting physician delivery of care with patient outcomes.

The late management expert, W. Edward Deming (2000), stated among his 14 principles for total quality management, was to "drive out fear". In order to drive out the fear across all the stakeholders described above, there must be increased trust and increased transparency. This is not, unfortunately, a new suggestion. Olejaz M, Juul N. A. , Rudkjøbing A., Okkels B. H., Krasnik A. \& Hernández-Quevedo C. (2012) report noted, "The use of information technology has received increasing attention within the health care sector. Strategies for digitalization of health information have been proposed a number of times but implementation has encountered problems because of lack of coordination” (xix). As if to further frustrate progress, as recently as September $30^{\text {th }}, 2014$, the agency known as DAK-E (Dansk Almenmedicinsk KvalitetsEnhed) has, “...stopped all data collection using Sentinel from general practices. For this very reason annual reports later than 2013 are not available" (www.dak-e.dk/damd/aarsberetninger).

A recent study regarding the use of research evidence in making policy decisions is instructive. In Vallgaarda's work (2014) the author found that often time interventions were not based on evidence. The author wrote:

Interventions where there is no or only weak evidence of welfareenhancing effect could not be defended from either a liberal or paternalistic standpoint. Others, and these include the National Board of Health, seem to consider it unethical and irresponsible not to act thereby leaving a people in a void while waiting for sufficient evidence. Doing something is better than doing nothing. (pp. 341,342)

Andermann, A., Pang, T., Newton, J. N., \& Panisset (2016) suggest:

It is important to strike a balance between making decisions that are not at all thought through versus overthinking every step. The systematic approach can therefore be helpful to avoid becoming too bogged down in the details to see the big picture, or even worse, being paralyzed by indecision when faced with a large number of perspectives and tradeoffs. (p. 6)

Finally, Marmot (2004 cited in Andermann) said, "Scientific findings do not fall on blank minds that get made up as a result. Science engages busy minds that have strong views about how things are and ought to be”.

Tradeoffs; doing something instead of doing nothing; busy minds; touchstones for all the stakeholders. The question is how much more can be done and how much more should be done. Is there one best solution? Perhaps the solution will be found in bringing all the parties together so they make work towards a common goal and restore their common focus on doing what is best for the patient and best for the community. Through cooperation and collaboration the gold mine of new knowledge and higher quality can be exploited by 
all the parties concerned, and all to the benefit of the patient. In closing, it seems that a nation like Denmark, an innovator and leader on so many social and ecological fronts would be anything less than enthusiastic about drawing upon a renewable and sustainable resource like health information. Like the many windmills that dot the Danish countryside, so too are there many gentle breezes within the healthcare system which offer new breath, new life for Denmark’s already exquisite health care system.

\section{Acknowledgements}

The author would like to thank the faculty and staff at the Research Unit of General Practice at Syddansk Universitet for administrative and logistical support. The author is also grateful to Wilkes University which provided a semester long sabbatical to support this research.

The author knows of no conflicts in the preparation of this article. There was no outside ethical review as there was no direct interaction with human subjects. All information collected was in the public domain.

\section{References}

Agency for Healthcare Research and Quality, United States Government (2015). HCAHPS Fact Sheet.

Andermann, A., Pang, T., Newton, J. N., \& Panisset, U. (2016). Evidence for health III: Making evidence-informed decisions that integrate values and context. Health Research Policy and Systems, 2016.

Andersen, P. T. \& Jensen, J. (2010). Healthcare reform in Denmark. Scandinavian Journal of Public Health, 38: 246-252.

Andersen, M. K., Pedersen, L. B., Siersma, V., Bro, F., Reventlow, S., Sondergaard, J., .. . Waldorff, F. B. (2017). Accreditation in general practice in Denmark: study protocol for a clusterrandomized controlled trial. Trials 2017 18:69.

Christiansen, T. (2012). Ten years of structural reform in Danish healthcare. Health Policy, 106, 114-119.

Dansk Almenmedicinsk KvalitetsEnhed Accessed: 8/18/17, https://www.dake.dk/damd/aarsberetninger.php

Deming, W. E. (2000). Out of the Crisis. MIT press.

Falstie-Jensen, A. M., Nørgaard, M., Hollnagel, E., Larsson, H., and Johnsen, S. P. (2015). Is compliance with hospital accreditation associated with length of stay and acute readmission? A Danish nationwide population-based study. International Journal for Quality in Health Care, Volume 27, Issue 6, 1 December 2015, Pages 451-458.

Falstie-Jensen, A. M., Larsson, H., Hollnagel, E., Nørgaard, M., Overgaard Svendsen, M. L., and Johnsen, S. P., (2015). Compliance with hospital accreditation and patient mortality: a Danish nationwide population-based study. International Journal for Quality in Health Care, 27(3), 165-174.

Kierkegaard, P. (2013). eHealth in Denmark: A case study. Journal of Medical Systems.

Kirkpatrick, I., Dent, M. \& Jespersen, P. K. (2011). The contested terrain of hospital management: Professional projects and healthcare reform in Denmark. Current Sociology 59 (4) 489-506.

Kristensen, T., Olsen, K. R., Kilsmark, J., Lauridsen, J. T. \& Pedersen, K. M (2012). Economies of scale and scope in the Danish hospital sector prior to radical restructuring plans) Health Policy, 106, 114-119. 
Kristensen, T., Olsen, K. R., Schroll, H., Thomsen, J. L. \& Halling, A. (2014). Association between fee for service expenditures and morbidity burden in primary care. European Journal of Health Economics, 15 (6), 599-610.

Lynge, E., Sandegaard, J. L., \& Rebolj, M. (2011). The Danish national patient register. Scandinavian Journal of Public Health, 39(Supp 7) 30-33.

Ministry of Health (20170). Healthcare in Denmark - An Overview ISBN: 978-87-7601-365-3.

Olejaz M, Juul N. A. , Rudkjøbing A., Okkels B. H., Krasnik A. \& Hernández-Quevedo C. (2012). Denmark: Health system review. Health Systems in Transition, Vol. 14 (2): 1 -92.

Organization for Economic Cooperation and Development (2013). OECD Reviews of care quality: Denmark. 15 April 2013. www.oecd.org/health/qulaityreviews.

Pedersen, K. M., Andersen, J. S., \& Sondergaard, J. (2012). Journal of the American Family Board of Medicine Vol 25 (March-April Supplement).

Vallgaarda, S. (2014). Ethics, equality and evidence in health promotion Danish guidelines for municipalities. Scandinavian Journal of Public Health, 42: 337-343.

Vrangbaek, Karsten (2016). Regionalization lessons from Denmark. HealthcarePapers, 16(1) July 2016: 21-26.

(C) 2018 by the author(s). This article is an open access article distributed under the terms and conditions of the Creative Commons Attribution license (http://creativecommons.org/licenses/by/4.0/). 